\title{
Gallbladder tuberculosis mimicking cholecystitis: A case report
}

\author{
Nur Prasetyo Nugroho ${ }^{1}$, Tutik Kusmiati ${ }^{1}$, Santoso Santoso ${ }^{2}$ \\ ${ }^{1}$ Department of Pulmonology and Respiratory Medicine, Faculty of Medicine, Universitas Airlangga, Dr. Soetomo General Teaching Hospital, Surabaya, Indonesia
} ${ }^{2}$ Division of Pulmonology, RKZ Vicentius A Paulo Hospital, Surabaya, Indonesia

Received: 2020-11-07.

Accepted: 2020-12-27

This work is licensed under a Creative Commons Attribution 4.0 International License

J Clin Med Kaz 2021; 18(2):72-74

\section{Corresponding author:}

Nur Prasetyo Nugroho.

Email: mazpraz.keren@gmail.com

ORCID: https://orcid.org/0000-0003-2197-355X

\section{Abstract}

Tuberculosis can affect extrapulmonary organs. Gallbladder tuberculosis is one of the rare extrapulmonary tuberculosis. Fewer than 120 cases have been published since reported in 1870 . We reported a 55-year-old woman who came to the hospital with a chief complaint of right upper abdominal pain. The abdominal ultrasonography obtained gallstones. The patient was initially diagnosed with acute cholecystitis, and laparoscopic cholecystectomy was performed. The histopathologic examination of the gallbladder showed chronic inflammation cells, while the smear showed acid-fast bacilli. The primary diagnosis was gallbladder tuberculosis. Antituberculosis treatment was performed with good clinical outcome and radiological improvement.

Key words: cholecystectomy, gallstones, histopathology, tuberculosis

\section{Introduction}

Tuberculosis (TB) can affect pulmonary or extrapulmonary organs. Abdominal $\mathrm{TB}$ is one of the extrapulmonary TB that is commonly found, but the hepatobiliary involvement is only less than $1 \%$ of all abdominal TB cases [1]. Gallbladder tuberculosis is a rare abdominal TB. Fewer than 120 cases worldwide have been published since it was first reported in 1870 by Gaucher [2]. Making the diagnosis of gallbladder TB remains a challenge [3]. Distinguish a gallbladder TB from other gallbladder diseases is still challenging [4]. Most gallbladder TB is diagnosed postoperatively with histopathological or tissue microbiology results [5]. In the endemic area of TB, identifying the rare cases of TB will play an essential role in eradicating tuberculosis from society.

\section{Case presentation}

A 55-year-old woman came to the hospital with right upper abdominal pain for three weeks. There was a decrease in appetite, weight loss, and night sweating. There was a history of gallstones since four years ago, but no complaints.

The general condition was good. Abdominal palpation obtained abdominal pain in the right upper quadrant when the patient was inhaling (Murphy sign). No laboratory abnormalities were found. The upperlower abdominal ultrasonography obtained two gallstones $(9.1 \mathrm{~mm}$ and $9.5 \mathrm{~mm})$ with a right pleural effusion (Figure $1)$.

Based on clinical and radiological data, the patient was diagnosed with acute cholecystitis due to gallstones. It was decided to perform a laparoscopy cholecystectomy. Bile tissue was resected (weight of 7.5 


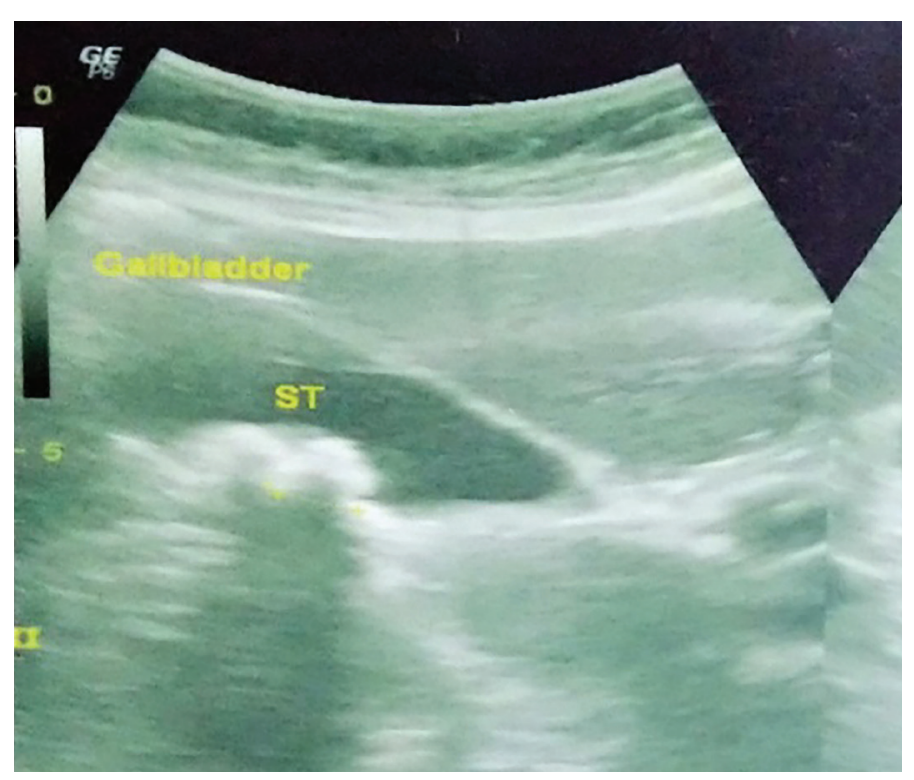

Figure 1. Two gallstones with the size of $9.5 \mathrm{~mm}$ and $9.1 \mathrm{~mm}$ were found in ultrasound

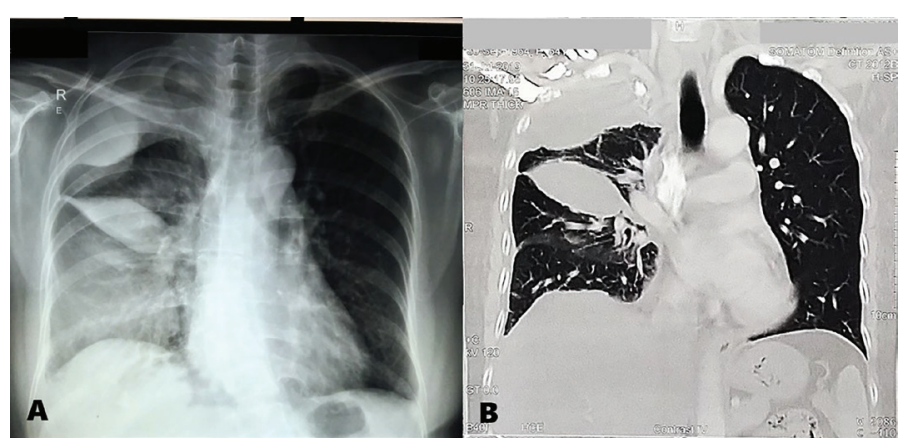

Figure 2. (A) Chest $X$-ray and (B) Chest $C T$ scan with contrast showing multi-localized right pleural effusion with compressive atelectasis right posterior pulmonary

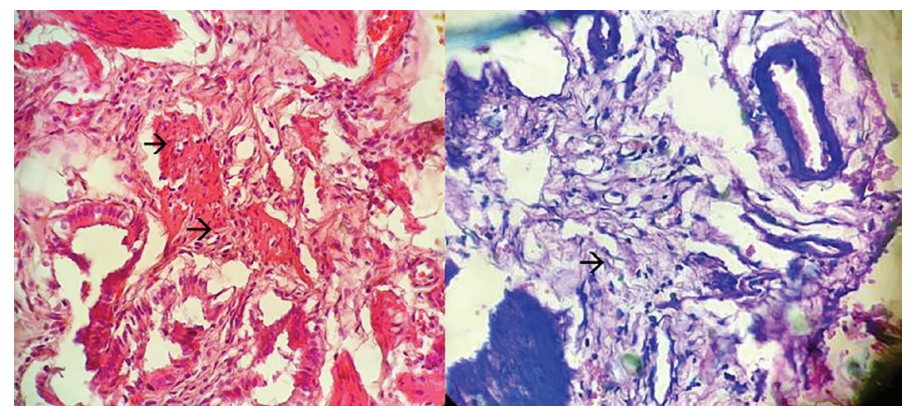

Figure 3. Gallbladder tissue examination (A) Chronic inflammation cells without malignant cells (pointed by arrow). (B) Acid-fast bacilli (pointed by arrow). The conclusion was that chronic cholecystitis could be caused by tuberculosis

grams and size $6 \times 3 \times 1 \mathrm{~cm})$. The gallbladder specimens have multiple adhesions and nodularity, which raises the suspicion of tuberculosis infection.

A chest X-ray and contrast chest CT scan was performed to determine the cause of pleural effusion (Figure 2). The results were not shown pneumonia or lung mass, but there were moderate multiloculated right pleural effusions that cause compressive atelectasis of the right pulmonary posterior segment (Figure 3). The pleural fluid analysis result was exudative with dominant monocyte cells and low glucose. The pleural fluid ADA was 52 (standard value is below 40), which indicates that the inflammation in the pleura was caused by tuberculosis.
Interferon Gamma Release Assay (IGRA) obtained positive results that indicate tuberculosis infection. Histopathological examination of the gallbladder showed inflammation of chronic cells without malignant cells, while the gallbladder smears found acid-resistant bacilli. The conclusion was that chronic cholecystitis could be caused by tuberculosis (Figure 3 ).

Based on the result, the patient was diagnosed with gallbladder TB and pleuritis TB. She was discharged after eight days of treatment. She was given an antituberculosis drug (ATD) for nine months due to extrapulmonary TB. After the treatment finished, the patient was declared cured by clinical and radiological improvement.

\section{Discussion}

Abdominal TB is one of the extrapulmonary TB that is often encountered. The percentage of abdominal TB events in developing countries is $12 \%$ of all extrapulmonary TB events [6]. Gallbladder TB is very rare, even in TB endemic areas. The percentage of incidence is only $1 \%$ of all abdominal TB events [7]. Gallbladder TB generally occurs in women over the age of 30 years [8].

The symptom that often occurs is a pain in the right upper abdomen, weight loss, nausea, vomiting, and diarrhea [9]. Other symptoms, such as jaundice, are rare. Most symptoms are associated with gallstones. Leukocytosis is commonly encountered [8].

The gallbladder generally immune to TB infection due to its thick walls and natural conditions of alkaline bile. The essential nature of bile inhibits the growth of Mycobacterium tuberculosis [3]. The presence of gallstones and obstruction is believed to reduce bile immunity against TB infection [2]. The route of spreading TB germs to the gall bladder can be through peritoneal, hematogenous, or lymphatic [3]. The most spread is through hematogenous [10]. In the ultrasound examination, the gallbladder's abdomen is replaced by a mass with stones inside. A study showed more than $70 \%$ of gallbladder TB cases accompanied by stones [11].

The typical histopathological finding of gallbladder tuberculosis is the presence of Langhans large cells and caseous granulomas. The discovery of Mycobacterium tuberculosis is one of the markers of biliary TB diagnosis [8]. The acid-fast bacilli are found in $60 \%$ of cases [12]. Histopathological features in the form of caseous granulomas and the presence of acid-fast bacilli are the final confirmation of diagnosis and gold standard of gallbladder TB [5-6].

The absence of pathognomonic diagnostic during preoperatively with acute cholecystitis symptoms makes surgery unavoidable as a therapy and diagnosis plan [11]. Gallbladder TB treatment is ATD for nine months by extending the advanced phase. Treatment evaluation is by clinical evaluation without culture or histopathological reevaluation [13].

\section{Conclusion}

In the endemic area of $\mathrm{TB}$, identifying the rare cases of TB will play an essential role in eradicating tuberculosis from society. Gallbladder TB is a rare disease. The diagnosis of gallbladder TB is made from histopathological or smear examination of the gallbladder. In tuberculosis endemic areas, we recommend that smear and histopathological examinations be routinely performed in patients undergoing cholecystectomy. Standard TB treatment is the first choice in gallbladder TB. The prognosis of this disease is usually good. 
Disclosures: There is no conflict of interest for all authors.

Acknowledgements: We want to express our sincere thanks to the 2nd Indonesia Tuberculosis Internasional Meeting (2nd INATIME) event which facilitated us to present this research on 27th August 2020 at Padang, Indonesia.

Funding: None.

\section{References}

1. Ul Haque MM, Whadva RK, Luck NH, Mubarak M. Primary hepaticobiliary tuberculosis mimicking gall bladder carcinoma with liver invasion: A case report. Pan Afr Med J. 2019; 32:1-5. https://doi: 10.11604/pamj.2019.32.68.10519. eCollection 2019.

2. Butt UI, Hameed B, Farooka MW, Ayyaz M, Chughtai A, Akbar MB. Tuberculosis of gallbladder mimicking carcinoma. $J$ Coll Physicians Surg Pakistan. 2017; 27:S845. https://www.jcpsp.pk/archive/2017/SS_Sep2017/08.pdf

3. Krishnamurthy G, Singh H, Rajendran J, Sharma V, Yadav TD, Gaspar BL, et al. Gallbladder tuberculosis camouflaging as gallbladder cancer - case series and review focusing on treatment. Ther Adv Infect Dis. 2016; 3(6):152-7. https://doi: 10.1177/2049936116678589

4. Liu Y, Wang K, Liu H. Gallbladder Tuberculosis Mimicking Gallbladder Carcinoma: A Case Report and Literature Review. Case Reports Hepatol. 2016; 2016(Figure 2):1-3. https://doi:10.1155/2016/3629708

5. Gupta A, Gupta A, Anjum R, Agrawal S, Mallik D. A comprehensive review on Primary gallbladder tuberculosis. Pol Prz Chir Polish J Surg. 2018; 90(2):10-2. https://doi:10.5604/01.3001.0011.7485

6. Xu XF, Yu RS, Qiu LL, Shen J, Dong F, Chen Y. Gallbladder tuberculosis: CT findings with histopathologic correlation. Korean J Radiol. 2011; 12(2):196-202. https://doi: 10.3348/kjr.2011.12.2.196

7. Swain B, Otta S, Mohapatra S. Tuberculous cholecystitis. Indian J Med Microbiol. 2013; 31(3):317. https://doi:10.4103/02550857.115672

8. de Melo VA, de Melo GB, Silva RL, Piva N, Almeida MLD. Tuberculosis of the cystic duct lymph node. Braz J Infect Dis. 2004; 8(1):112-4. https://doi:10.1590/s1413-86702004000100009

9. Dahuja A, Dahuja G, Kaur R, Bansal K. Isolated Tuberculosis of Talus: A Case Report. Malaysian Orthop J. 2014; 8(1):61-2. https:// doi:10.5704/MOJ.1403.001

10. Kumar P, Hazrah P, Taneja A, Ahuja A, Sharma D. Rare presentation of gall bladder tuberculosis in a non-immuno-compromised patient. Clin Pract. 2015; 5(2):5-6. https://doi: 10.4081/cp.2015.754

11. Masood I, Rasheed H, Lutfi IA, Raheem A. A pre-operative diagnostic dilemma and incidental prevalence in histopathology: Retrospective analysis of gallbladder tuberculosis. Pakistan J Surg [Internet]. 2017; 33(1):79-82. http://www.pjs.com.pk/journal_ pdfs/jan_mar17/79.pdf

12. Djajakusuma, Timbol, Ong. Clinicopathologic Features of Hepatobiliary Tuberculosis: A Ten-Year Retrospective Autopsy Series. Philipp Soc Gastroenterol. 2015; http:/giresearch.ph/docs/researchpapers/Co\%20-\%20Hepatobioliary\%20TB.pdf

13. Departemen Kesehatan Republik Indonesia. Pedoman Nasional Pelayanan Kedokteran Tatalaksana Tuberkulosis. 2019 ; 1-139. 